\title{
Перспективы Приполярного Урала на золото-сульфидное прожилково-вкрапленное оруденение: прогнозирование нетрадиционного оруденения в складчато-надвиговых поясах
}

\section{Савчук Ю.С., Волков А.В.}

Институт геологии рудных месторождений, петрографии, минералогии и геохимии РАН, Москва, yurasavchuk@yandex.ru

Аннотация. Хальмерьинский рудный узел на территории Приполярного Урала включает три месторождения золота и приурочен к Омрасьшорской разломно-сдвиговой зоне среди докембрийских образований Центрально-Уральского поднятия. Предполагается продолжение этой рудоконтролирующей зоны далее на северо-восток. Сделан вывод о перспективности нижнепалеозойских отложений на золото-сульфидное прожилково-вкрапленное оруденение.

Ключевые слова: Приполярный Урал, золото, разломно-сдвиговая зона, золото-сульфидные руды.

\section{Prospects of the Subpolar Urals for gold-sulfide vein-disseminated mineralization: forecasting unconventional mineralization in fold-thrust belts}

Savchuk Yu.S., Volkov A.V.

Institute of Geology of Ore Deposits, Petrography, Mineralogy and Geochemistry RAS, Moscow, yurasavchuk@yandex.ru

Abstract. The Khalmery ore cluster in the Subpolar Urals includes three gold deposits and is confined to the Omrashorsk fault-shear zone among the Precambrian formations of the Central Ural uplift. It is assumed that this orecontrolling zone will continue further to the northeast. It is concluded that the Lower Paleozoic deposits are promising for gold-sulfide vein-disseminated mineralization.

Key words: Subpolar Urals, gold, fault-strike-slip zone, gold-sulfide ores.

Традиционно критерием перспективности площадей на рудное золото служило наличие крупных и богатых россыпей. В результате такого подхода были открыты многочисленные месторождения золота на Южном Урале, связанные с Тагило-Магнитогорской и Восточно-Уральской зонами, сложенными в основном палеозойскими осадочно-вулканогенными и интрузивными породами (Золото..., 1993; Золоторудные..., 2010; Коротеев и др., 2001). Разведано достаточно крупное месторождение золота в подобной позиции и на Полярном Урале (Мансуров, 2009).

Центрально-Уральское поднятие, к западу от Главного Уральского разлома, сложено полиметаморфическими образованиями предположительно рифей-вендского возраста и является эксгумированным складчато-метаморфическим фундаментом (Пучков, 2000), серией надвиговых структур расчлененным на ряд пластин. На Приполярном Урале, на площади развития метатерригенных и метавулканогенных образований Центрально-Уральского поднятия, проявления коренного золота пока немногочисленны (Коротеев и др., 2001; Озеров, 1998; Савчук, Волков, Аристов, 2018; Серавкин, 2009; Тарбаев и др., 1996).

Так, в Хальмерьинском рудном узле, наряду с богатыми россыпями, выявлены три небольших коренных месторождения (Ким, 2004) и ряд рудопроявлений, увязываемых в протяженный северо-восточный рудный тренд, вдоль Омрасьшорской разломно-сдвиговой зоны. Здесь докембрийские образования гетерогенно-контрастного состава тектонически перекрывают полиметаморфические толщи Хобеизского срединного массива и слагают сложное сооружение дуплексового строения (Савчук, Волков, 2020), относимое к Лемвинско-Народнинской покровно-чешуйчатой зоне. Омрасьшорская система разломов прослежена более чем на 25 км, при ширине зоны до 4 км. Золотые месторождения располагаются на разных уровнях шарьяжно-складчатого сооружения и 
(a)

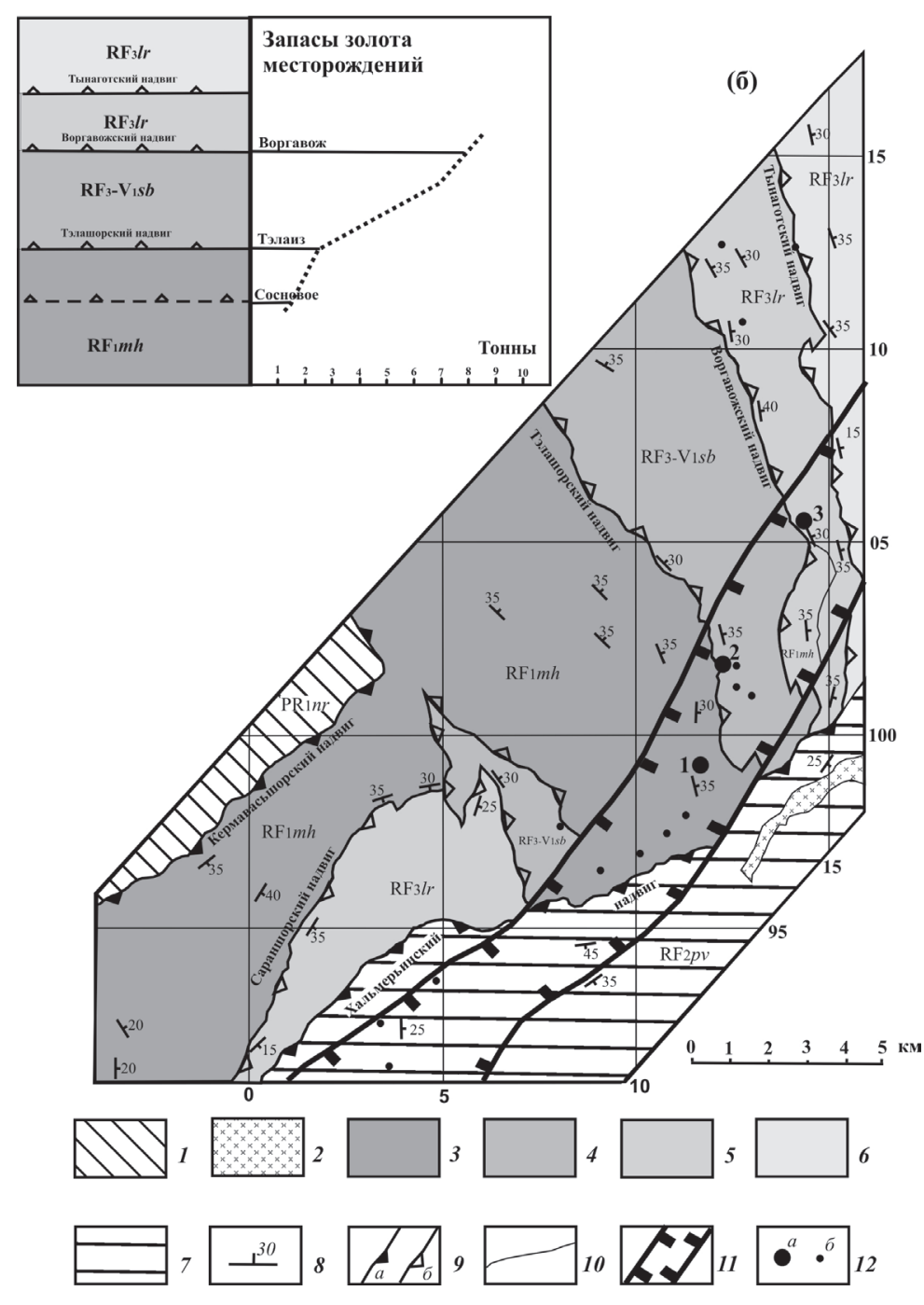

Рис. 1. Положение золотых месторождений в разрезе (а) и структурногеологическая схема Хальмерьинской площади (б). 1-2 - Хобеизский массив, 1 - няртинский комплекс $\mathrm{PR}_{1} n r$ : гранито-гнейсы, кристаллические сланцы, амфиболиты; 2 - николайшорский комплекс $\gamma \mathrm{PR}_{1} n$ : порфировидные гнейсограниты; 3 - Хальмерьинский блок маньхобеинская свита $\mathrm{RF}_{1}$ ? $m h$ : порфировидные гранито-гнейсы, метариолиты, кварцито-гнейсы; 4-6 - Тынаготский блок: 4 - Тэлаизский пакет - саблегорская свита $\mathrm{RF}_{3}-\mathrm{V}_{1} s b$ : сланцы серицит-хлоритальбит-кварцевые, мусковит-хлориткварцевые, актинолит-хлоритовые, хлорит-амфиболовые, полевошпатамфиболовые, слюдисто-хлоритовые, хлорит-мусковитовые, мусковитполевошпатовые, вторичные кварциты, 5 - Воргавожский пакет - лорцемпейская свита $\mathrm{RF}_{3} l r$ : сланцы хлорит-мусковитальбит-кварцевые, альбит-эпидотхлоритовые, метаандезибазальты, 6 - Тынаготский пакет - лорцемпейская свита $\mathrm{RF}_{3} l r$ : сланцы хлорит-мусковит-альбиткварцевые, альбит-эпидот-хлоритовые, метаандезибазальты; 7 - Народнинский блок - пуйвинская свита $\mathrm{RF}_{2} p v$ : хлоритэпидот-альбит-актинолитовые, биотитмусковит-альбит-кварцевые сланцы, субвулканические метадолериты; 8 - элементы залегания сланцеватости; 9 - надвиги:

а - главные, б - второстепенные; 10 - разломы крутопадающие; 11 - границы Омрасьшорской системы разломов; 12 - золоторудные месторождения: a - Сосновое -1 , Тэлаиз - 2, Воргавож - 3, б - проявления золота.

Fig. 1. Position of gold deposits in the section (a) and structural-geological scheme of the Khalmery area (b). 1-2 - Khobeiz massif, 1 - Nyarta complex PR $n r$ : granite-gneisses, crystalline schists, amphibolites; 2 - Nikolayshor complex $\gamma \mathrm{PR}_{1} n$ : porphyritic gneiss-granites; 3 - Khalmery block - Mankhobei suite $\mathrm{RF}_{1}$ ? $m h$ : porphyry granitegneisses, metaryolites, quartzite-gneisses; 4-6 - Tynagotsky block: 4 - Telaiz packet - Sablegorskaya suite $\mathrm{RF}_{3}-\mathrm{V}_{1} s b$ : sericite-chlorite-albite-quartz schists, muscovite-chlorite-quartz, actinolite-chlorite, chlorite-amphibole, feldspar-amphibole, micaceous chlorite, chlorite-muscovite, muscovite-feldspar, secondary quartzites, 5 - Vorgavozhsky packet - Lorcempey suite $\mathrm{RF}_{3} \mathrm{lr}$ : chlorite-muscovite-albite-quartz schists, albite-epidote-chlorite, metaandesite-basalts, 6 Tynagotsky packet - Lorcempey suite $\mathrm{RF}_{3} l r$ : chlorite-muscovite-albite-quartz shale, albite-epidote-chlorite shale, metaandesite; 7 - Narodninskiy block - Puivinskaya suite $\mathrm{RF}_{2} p v$ : chlorite-epidote-albite-actinolite, biotite-muscovitealbite-quartz schists, subvolcanic metadolerites; 8 - elements of shale occurrence; 9 - thrusts: $a-$ major, $b$ - minor; 10 - steeply dipping faults; 11 - boundaries of the Omrashorsk fault system; 12 - gold deposits: a - Sosnovoye -1 , Telaiz - 2, Vorgavozh $-3, \mathrm{~b}-$ gold occurrences.

вертикальный размах золото-сульфидно-кварцевого оруденения, со свободным золотом, оценивается не менее чем в 4 км (рис. 1).

В пределах выявленного тренда также наблюдается смена характера минерализации, от жильно-прожилковой (Сосновое - низы рудной колонны) на юго-западном фланге, до прожилкововкрапленной (Воргавож - верхи рудной колонны) на северо-востоке (Савчук, Волков, Аристов, 
Рис. 2. Предполагаемая перспективная позиция золотосульфидного прожилково-вкрапленного оруденения в Лемваизском аллохтоне (с использованием данных А.Ф. Филатова, С.И. Логвина).

1 - Хобеизский срединный массив: гранито-гнейсовая $\mathrm{PR}_{1}$ ? формация; 2 - Лемвинско-Народинская покровно-чешуйчатая зона: рифтогенные образования контрастного состава RF-V; 3 - Лемваизский аллохтон $\mathrm{Pz}_{1}$ : внизу аповулканогенные альбитхлорит-эпидот-амфиболовые, хлорит-альбит-амфиболовые сланцы, тела габбро-долеритового комплекса; выше переслаивание алевропесчаников, алевросланцев, с прослоями гравелитов; в верху графитоидные сланцы, кварциты, филлиты, кислые эффузивы; 4 - Неркаюский метаморфический комплекс $\mathrm{PR}_{1}$ : гнейсы, кристаллические сланцы, амфиболиты, гранат-глаукофановые сланцы; 5 - Тагило-Магнитогорская мегазона; 6 - Главный Уральский глубинный разлом (ГУГР); 7 - основные надвиги; 8-9 - границы Омрасьшорской системы разломов: 8 - установленные, 9 - предполагаемые; 10 - разломы; 11 - золоторудные месторождения; 12 - линии геохимических профилей; 13 - участки профилей с повышенными содержаниями золота ( $\geq 0.1$ г/т) в пробах; 14 - предполагаемая перспективная позиция золото-сульфидного прожилково-вкрапленного оруденения.

Fig. 2. Prospective prospective position of gold-sulfide vein-disseminated mineralization in the Lemvaiz allochthon (using data from A.F. Filatov, S.I. Logvin). 1 - Khobeiz median massif: granite-gneiss PR1? formation; 2 - Lemvinsko-Narodinskaya nappe-scaly zone: riftogenic formations of contrasting composition RF-V; 3 - Lemvaiz allochthon Pz1: below the apovolcanic albite-chlorite-epidote-amphibole, chlorite-albite-amphibole schists, bodies of the gabbro-dolerite complex; higher interbedding of silty sandstones, silty shales, with interbeds of gravelstones; at the top there are graphitoid schists, quartzites, phyllites, felsic effusive rocks; 4 - Nerkayu metamorphic complex PR1: gneisses, crystalline schists, amphibolites, garnet-glaucophane schists; 5 - Tagilo-Magnitogorsk megazone; 6 - Main Ural deep-seated fault (GUGR); 7 - main thrusts; 8-9 - boundaries of the Omrashorsk fault system: 8 - established, 9 - assumed; 10 - faults; 11 - gold deposits; 12 - lines of geochemical profiles; 13 - sections of profiles with high gold contents $(\geq 0.1 \mathrm{~g} / \mathrm{t})$ in samples; 14 - the prospective prospective position of the gold-sulfide vein-disseminated mineralization.

2018). В этом же направлении увеличиваются размах и масштабы рудной минерализации. На месторождении Сосновое (1.4 т) ширина развития золоторудной минерализации между двумя четко выраженными разломами составляет около 140 м; на месторождении Тэлаиз (2.4 т) общая ширина непротяженных рудовмещающих тектонических трещин около 500 м; и на месторождении Воргавож (7.7 т) ширина зоны мелкой трещиноватости достигает 1200 м. Таким образом, снизу вверх по 
разрезу происходит постепенное угасание степени тектонизированности рудовмещающей толщи, при значительном увеличении ширины проявления.

Предполагается, что Омрасьшорская система разломов может продолжаться и далее на северо-восток, в пределы нижнепалеозойских метатерригенных и метавулканогенных толщ Лемваизского аллохтона, тектонически перекрывающего докембрий Лемвинско-Народнинской покровночешуйчатой зоны. В этом случае на этом продолжении вполне вероятно наблюдать развитие широкой зоны мелкой трещиноватости.

Позиция и золото-сульфидно-кварцевое оруденение Хальмерьинского рудного узла характерны для орогенных месторождений в складчатых поясах. На типовой вертикальной зональности орогенных месторождений, описанной Д.И. Гровсом (Groves et al., 1998), выше по разрезу располагается золото-сульфидная прожилково-вкрапленная минерализация, с небольшим количеством свободного золота, обычно не дающая россыпей. Здесь уже отсутствие, либо слабая россыпная золотоносность не могут быть критерием для оценки территории на коренное золотое оруденение. Для проверки этой гипотезы, в пределах Лемваизского аллохтона были проведены региональные геохимические исследования, сконцентрированные на 3 профилях значительной протяженности (рис. 2). По этим профилям осуществлялся отбор рыхлого материала фракции $\leq 1$ мм с глубины до 60 см, с шагом 20 м. Пробы анализировались химико-спектральным анализом на золото в Бронницкой геолого-геохимической экспедиции. В результате проведенных исследований выделена предполагаемая перспективная позиция золото-сульфидного прожилково-вкрапленного оруденения в Лемваизском аллохтоне (рис. 2).

Выявленные закономерности развития структуры и изменения масштабов золотых месторождений в разрезе шарьяжно-складчатых сооружений, могут использоваться в прогнозных, поисковых, и металлогенических исследованиях в других складчатых поясах, в т.ч. для Верхояно-Колымского складчато-надвигового пояса, где серия золотых месторождений контролируется зонами региональных взбросо-сдвигов. Так, в пределах Омчакского разлома выявлена серия золоторудных месторождений, которые контролируются структурами с изменяющимися углами падения и фактически, вверх по разрезу, углы закономерно увеличиваются, т.е. эти нарушения от надвиговых (пологих) внизу, постепенно переходят во взбросовые (крутые) в верхней части (Савчук, Волков, Аристов, 2019). В этом же направлении увеличивается рудный потенциал, а в составе золото-сульфидно-кварцевой минерализации начинает возрастать доля прожилково-вкрапленной составляющей.

Таким образом, структурные наблюдения на золоторудных объектах в пределах складчатонадвиговых поясов позволяют реставрировать общее строение гидротермальной колонны и на этой основе прогнозировать степень перспективности конкретных площадей и особенности строения возможных рудных проявлений.

Работа выполнена в рамках темы Госзадания ИГЕМ РАН.

\section{Литература}

1. Золото Урала (к 250-летию золотой промышленности Урала) (ред. В.А. Коротеев). Екатеринбург. Изд-во: Наука. 1993. 209 с.

2. Золоторудные месторождения России. (ред. Константинов М.М.). М. Изд-во: Акварель. 2010. 349 с.

3. Ким Г.П. Особенности геологического строения и характеристика золоторудных объектов Хальмерьинской площади (Приполярный Урал). Полярный Урал - стратегия освоения // Труды II ПолярноУральской научно-практической конференции. 11-12.02.2004, Салехард-Тюмень. Изд-во: ТюменГУ. 2004. C. 210-213.

4. Коротеев В.А., Огородников В.Н., Поленов Ю.А., Сазонов В.Н. Месторождения золота Урала. Екатеринбург. Изд-во: УГГГА. 2001. 622 с.

5. Мансуров Р.Х. Геологическое строение Петропавловского золоторудного месторождения. Полярный Урал // Руды и металлы. 2009. № 5. С. 70-74.

6. Озеров В.С. Особенности металлогении золота области Центрально-Уральского поднятия на севере Урала // Золото, платина и алмазы Республики Коми и сопредельных регионов // Матер. Всерос. конф. 17-19.02.1998. ИГ Коми НЦ УрО РАН. Сыктывкар. Изд-во: Геопринт. 1998. С. 14-16.

7. Пучков В.Н. Палеогеодинамика Южного и Среднего Урала. Уфа. Изд-во: Даурия. 2000. 146 с. 
8. Савчук Ю.С., Волков А.В., Аристов В.В. Перспективы золотоносности докембрийских комплексов Приполярного Урала // Литосфера. 2018. Т. 18. № 2. С. 280-294.

9. Савчук Ю.С., Волков А.В., Аристов А.А. О структурной зональности месторождений золота в зоне Тенькинского разлома (Центрально-Колымский регион) // Всероссийская конференция. Х Косыгинские чтения. Тектоника, глубинное строение и минерагения Востока Азии. Хабаровск. 10-12.09. 2019. C. 215-217.

10. Савчук Ю.С., Волков А.В. Структурные особенности допалеозойских толщ Центрально-Уральского поднятия Северного и Приполярного Урала и связь с золотоносностью региона // Геотектоника. 2020. № 6. С. 59-76.

11. Серавкин И.Б. Эндогенная металлогения золота Урала (обзор, статья 1-я - Полярный, Приполярный, Северный и Средний Урал) // Геологический сборник № 8. Информационные материалы. Уфа. Изд-во: ИГ УНЦ РАН. 2009. С. 164-176.

12. Тарбаев М.Б., Кузнецов С.К., Моралев Г.В., Соболева А.А., Лапутина И.П. Новый золото-палладиевый тип минерализации в Кожимском районе Приполярного Урала (Россия) // Геология рудных месторождений. 1996. Т. 38. № 1. С. 11-25.

13. Groves D.I., Goldfarb R.J., Gebre-Mariam M., Hagemann S.G., Robert F. Orogenic gold deposits - a proposed classification in the context of their crustal distribution and relationship to other gold deposit types // Ore Geology Rev. 1998. V. 13. P. 7-27. 